\title{
High Levels of Circulating Type II Collagen Degradation Marker (CTx-II) Are Associated with Specific VDR Polymorphisms in Patients with Adult Vertebral Osteochondrosis
}

\author{
Sabina Cauci ${ }^{1}$, Marco Viganò ${ }^{2}$ (D), Laura de Girolamo ${ }^{2}$ (D), Paola De Luca ${ }^{2}$, \\ Carlotta Perucca Orfei ${ }^{2}$, Giuseppe Banfi ${ }^{3}$, Giovanni Lombardi ${ }^{4}$, Marco Brayda-Bruno ${ }^{5}$ \\ and Alessandra Colombini ${ }^{2, *}$ (iD \\ 1 Department of Medicine, University of Udine, 33100 Udine, Italy; sabina.cauci@uniud.it \\ 2 Orthopaedic Biotechnology Lab, IRCCS Galeazzi Orthopaedic Institute, Via R. Galeazzi 4, 20161 Milan, Italy; \\ marco.vigano@grupposandonato.it (M.V.); laura.degirolamo@grupposandonato.it (L.d.G.); \\ deluca.paola@grupposandonato.it (P.D.L.); carlotta.perucca@grupposandonato.it (C.P.O.) \\ 3 Vita-Salute San Raffaele University, 20132 Milan, Italy; banfi.giuseppe@fondazionesanraffaele.it \\ 4 Laboratory of Experimental Biochemistry \& Molecular Biology, IRCCS Galeazzi Orthopaedic Institute, \\ 20161 Milan, Italy; giovanni.lombardi@grupposandonato.it \\ 5 Department of Orthopedics and Traumatology, Spine Surgery III-Scoliosis Unit, IRCCS Galeazzi \\ Orthopaedic Institute, 20161 Milan, Italy; marco.brayda@spinecaregroup.it \\ * Correspondence: alessandra.colombini@grupposandonato.it; Tel.: +39-0266214067; Fax: +39-0266214048
}

Received: 26 July 2017; Accepted: 25 September 2017; Published: 29 September 2017

\begin{abstract}
Both vitamin D and collagen have roles in osteocartilaginous homeostasis. We evaluated the association between the circulating 25-hydroxyvitamin D (25(OH)D), type I and II collagen degradation products (CTx-I, and CTx-II), and four vitamin D receptor gene (VDR) polymorphisms, in Italian males affected by low back pain (LBP) due to herniation/discopathy and/or vertebral osteochondrosis. FokI, BsmI, ApaI, and TaqI VDR-polymorphisms were detected through PCR-restriction fragment length polymorphism (RFLP), and circulating $25(\mathrm{OH}) \mathrm{D}, \mathrm{CT} x-\mathrm{I}$ and $\mathrm{CT} x-\mathrm{II}$ were measured by immunoassays in 79 patients (of which 26 had osteochondrosis) and 79 age-, sex- and body mass index (BMI)-matched healthy controls. Among all 158 subjects, carriers of $F F$ and $F f$ genotypes showed lower $25(\mathrm{OH}) \mathrm{D}$ than $\mathrm{ff}$, which suggested a higher depletion of vitamin D in $F$ allele carriers. Higher CTx-I concentrations were observed in TT versus Tt among controls, and Tt versus $t t$ among LBP cases, which suggested a higher bone-cartilaginous catabolism in subjects bearing the $T$ allele. Higher CTx-II concentrations were observed in patients with osteochondrosis bearing $F F, b b, T T$, or $A a$ genotypes in comparison with hernia/discopathy patients and healthy controls. Vertebral osteochondrosis shows peculiar genotypic and biochemical features related to vitamin D and the osteocartilaginous metabolism. Vitamin D has roles in the pathophysiology of osteochondrosis.
\end{abstract}

Keywords: adult vertebral osteochondrosis; Italian males; VDR polymorphisms; type II collagen

\section{Introduction}

A recent Italian cohort study performed on adult patients with low back pain (LBP) confirmed by magnetic resonance imaging (MRI) found that 26.8\% (40/149) of male patients and $8.5 \%(10 / 118)$ of female patients had spine osteochondrosis [1,2].

The vertebral osteochondrosis, or Scheuermann disease, belongs to the osteochondrosis group of pathologies, which are characterized by the presence of degenerative necrotic ischemic processes of the ossification nuclei at the growing epiphyses and apophyses beginning in childhood and 
adolescence [3,4]. Scheuermann disease is the most common cause of structural kyphosis in adolescence. A prevalence of $18-40 \%$ of Scheuermann disease radiological signs was reported in the general population, with more males affected [5].

In some cases, especially when the pathology is present at the lumbar level, spine osteochondrosis is asymptomatic, and the related LBP can appear only in adulthood [6-9].

Apparently, the vertebral osteochondrosis involves defects in the cartilage endplate of vertebrae [10], which is devoted to the vertical growth of the vertebral body. The clinical/radiological manifestations of this pathology are the presence of an irregular vertebral endplate, disc narrowing, subchondral sclerosis, Schmorl's node (upper or lower disc herniation into the spongious bone of the vertebral body), anterior wedging of the vertebral bodies, and kyphosis [11,12]. However, kyphosis can be present or absent [13].

Morphological studies of spinal osteochondrosis showed the presence of sparse disorganized fibrils in the cartilage matrix, which are likely associated with disturbed collagen synthesis and an abnormal collagen/proteoglycan ratio $[11,14,15]$.

The etiology of osteochondrosis is elusive, and likely multifactorial. Evidence highlights the involvement of an impaired blood supply causing oxygen and nutrition insufficiency at the vertebral ossification nuclei and consequent cell necrosis [4], but mechanical damage/repeated microtrauma can also contribute [8]. Moreover, a genetic influence was observed: a high prevalence of osteochondrosis in male monozygotic twins $[16,17]$ and an inheritance of the autosomal dominant type $[18,19]$ support the genetic etiology hypothesis.

An increasing number of research studies point to vitamin D involvement not only in spinal bone homeostasis, but also in cartilaginous tissues, and consequently in etiology of LBP [20]. Virtually all actions of vitamin D occur by activation of the vitamin D nuclear receptor (VDR), which after translocation into the cell nuclei and by binding to thousands of vitamin D recognition sites (VDREs) can up- and downregulate hundreds of human genes [21]. Notably, VDR is present in osteoblasts [22] and intervertebral disc (IVD) cells [23,24]. Such cells can be found in the osteocartilaginous osteophytes, i.e., neo-formations showing some stages of bone turnover and remodeling. Osteophytes likely represent a healing response of the disc to structural degeneration, which involves interplay between the hyperplasia of bone tissue and the neo-formation of cartilage. In view of the importance of the vitamin D hormone in osteocartilaginous metabolism, the vitamin D endocrine system pathways might have a crucial role in the development of IVD and osteochondrosis pathological features [20]. Of note, polymorphisms in the vitamin D receptor gene $(V D R)$ have been showed to be associated with LBP and particularly with spine pathologies involving the IVD, such as herniation and discopathies, or affecting both IVD and endplate, such as osteochondrosis [20,25]. Nevertheless, there is no agreement concerning these associations [26], and there are no functional studies evaluating the real influence of $V D R$ genetic variants on IVD pathologies [20].

By analyzing the four most studied VDR polymorphisms, namely FokI, BsmI, ApaI, and TaqI in an Italian cohort of LBP patients, a link was observed between the aforementioned genetic variants and specific LBP-associated lumbar spine pathologies $[1,2,27]$. In particular, peculiar associations were observed between the $F F, A a$, and $b b A a T T$ genotypes, the $T$ and $F$ alleles (but in males only [2]), and the increased risk of developing vertebral osteochondrosis [1,27]. Collagen homeostasis likely has important roles in IVD diseases [28]. Of interest, in a recent study, males with IVD pathologies, particularly those with osteochondrosis, showed higher cross-linked type 2 collagen fragments, called CTx-II (which is considered a marker of cartilage metabolism) than healthy controls [21]. Thus, LBP patients affected by IVD diseases, and particularly those with vertebral osteochondrosis, present peculiar genotypical/biochemical and phenotypical features, which distinguish them from the general LBP group of patients that have spine pathologies, but without osteochondrosis.

In this context, the aim of this study is to evaluate the possible association between the plasma vitamin D concentrations and the circulating levels of type I and II collagens C-telopeptides' degradation products (CTx-I and CTx-II, respectively), as markers of osteocartilaginous damage, and the presence of specific genotypes/alleles in the VDR polymorphic sites in a cohort of Italian males affected by two 
LBP-related conditions, osteochondrosis and disc herniation/discopathy without osteochondrosis, versus healthy controls. The results of the present study will allow researchers to better understand the molecular basis of the modulation effects of $V D R$ genetic variants in disc degeneration-related pathologies.

\section{Results}

\subsection{Genotypes and Alleles Frequencies in the Study Population}

LBP patients $(n=79)$ and healthy controls $(n=79)$ had an age range of 19-62 years (mean \pm SD $40.8 \pm 9.2$ years), and a BMI range of 18.3-37.2 (mean \pm SD $25.9 \pm 3.8 \mathrm{~kg} / \mathrm{m}^{2}$ ); cases and controls did not differ in terms of age and BMI. Among patients, 33 had herniation without discopathy, 20 had discopathy with $(n=14)$ or without $(n=6)$ herniation, and 26 had osteochondrosis with $(n=20)$ or without $(n=6)$ discopathy and herniation.

The frequencies of FokI, BsmI, ApaI, and TaqI VDR genotypes and alleles in healthy controls $(n=79)$, LBP cases $(n=79)$ and two different pathological subgroups constituted of LBP patients with hernia/discopathy without osteochondrosis $(n=53)$ and patients with osteochondrosis $(n=26)$ are reported in Table 1 . The frequencies of genotypes and alleles of the four $V D R$ polymorphisms were consistent with those reported in previously published studies from the same research group [1,2,27]. Statistically significant differences were evaluated by comparing patients groups with healthy controls, and by comparing the two patient subgroups. The TT genotype and $T$ allele were more frequent in osteochondrosis patients than in the healthy controls (Odds Ratio (OR) $=3.3,95 \%$ Confidence Interval $(\mathrm{CI})=1.3-8.2, p=0.012 ; \mathrm{OR}=2.7,95 \% \mathrm{CI}=1.3-5.6, p=0.009$, respectively). An increased tendency for the risk to develop osteochondrosis was observed for $b$ allele carriers compared with healthy controls ( $\mathrm{OR}=1.8,95 \% \mathrm{CI}=0.9-3.6, p=0.084)$. Consequently, the $B$ allele tended to be protective for osteochondrosis. No differences were noted between hernia/discopathy and osteochondrosis patients.

Table 1. Frequencies of vitamin D receptor (VDR) genotypes and alleles in healthy controls, all lower back pain (LBP) cases, and two different pathological LBP subgroups (hernia/discopathy without osteochondrosis and osteochondrosis positive patients).

\begin{tabular}{|c|c|c|c|c|c|}
\hline \multicolumn{2}{|c|}{$V D R$} & \multirow{2}{*}{$\begin{array}{c}\text { Healthy Controls } \\
n=79(\%)\end{array}$} & \multirow{2}{*}{$\begin{array}{c}\text { All LBP Cases } \\
n=79(\%)\end{array}$} & \multirow{2}{*}{$\begin{array}{c}\text { Hernia/Discopathy } \\
n=53(\%)\end{array}$} & \multirow{2}{*}{$\begin{array}{c}\text { Osteochondrosis } \\
n=26(\%)\end{array}$} \\
\hline & & & & & \\
\hline \multirow{12}{*}{ genotypes } & $F F$ & $32(40.5)$ & $36(45.6)$ & $27(50.9)$ & $9(34.6)$ \\
\hline & $F f$ & $34(43.0)$ & $37(46.8)$ & $22(41.5)$ & $15(57.7)$ \\
\hline & $f f$ & $13(16.5)$ & $6(7.6)$ & $4(7.5)$ & $2(7.7)$ \\
\hline & $B B$ & $14(17.7)$ & 14 (17.7) & $12(22.6)$ & $2(7.7)$ \\
\hline & $B b$ & $39(49.4)$ & $36(45.6)$ & $25(47.2)$ & $11(42.3)$ \\
\hline & $b b$ & $26(32.9)$ & $29(36.7)$ & $16(30.2)$ & $13(50.0)$ \\
\hline & TT & $26(32.9)$ & $38(48.1)$ & $22(41.5)$ & $16(61.5)$ \\
\hline & $T t$ & $40(50.6)$ & $31(39.2)$ & $22(41.5)$ & $9(34.6)$ \\
\hline & $t t$ & $13(16.5)$ & $10(12.7)$ & $9(17.0)$ & $1(3.8)$ \\
\hline & $A A$ & $32(40.5)$ & $25(31.7)$ & $19(35.8)$ & $6(23.1)$ \\
\hline & $A a$ & $34(43.0)^{\wedge}$ & $46(58.2)$ & $30(56.6)$ & $16(61.5)^{\wedge}$ \\
\hline & $a a$ & $13(16.5)$ & $8(10.1)$ & $4(7.5)$ & $4(15.3)$ \\
\hline \multirow{8}{*}{ alleles } & $F$ & $98 / 158(62.0)$ & $109 / 158(69.0)$ & $76 / 106$ (71.7) & $33 / 52(63.5)$ \\
\hline & $f$ & $60 / 158(38.0)$ & $49 / 158$ (31.0) & $30 / 106(28.3)$ & $19 / 52(36.5)$ \\
\hline & $B$ & $67 / 158(42.4)^{\wedge}$ & $64 / 158(40.5)$ & $49 / 101(48.5)$ & $15 / 52(28.8)^{\wedge}$ \\
\hline & $b$ & $91 / 158(57.6)^{\wedge}$ & $94 / 158(59.5)$ & $52 / 101(51.5)$ & $37 / 52(71.2)^{\wedge}$ \\
\hline & $T$ & $92 / 158(58.2)$ & $107 / 158(67.7)$ & $66 / 106(62.3)$ & $41 / 52(78.8)$ \\
\hline & $t$ & $66 / 158(41.2)$ & $51 / 158(32.3)$ & $40 / 106$ (37.7) & $11 / 52(21.2)$ \\
\hline & $A$ & $98 / 158(62.0)$ & $96 / 158(60.8)$ & $68 / 106(64.1)$ & $28 / 52(53.8)$ \\
\hline & $a$ & $60 / 158(38.0)$ & $62 / 158$ (39.2) & $38 / 106(35.9)$ & $24 / 52(46.2)$ \\
\hline
\end{tabular}

Significant differences were indicated in bold, ^ indicated a tendency by comparing LBP patients versus healthy controls. 
Present results concerning the osteochondrosis patients confirmed previously published data in a larger cohort of LBP Italian patients [1,27].

\subsection{FokI Polymorphism, and 25(OH)D, CTx-I and CTx-II Circulating Concentrations}

Concentrations of plasma $25(\mathrm{OH}) \mathrm{D}, \mathrm{CTx}-\mathrm{I}$ and CTx-II were evaluated according to specific genotypes and alleles in all 158 study subjects, and specifically in 79 healthy controls, and in the 79 LBP patients. Additionally, LBP cases were further subdivided in 53 hernia/discopathy patients without osteochondrosis, and in 26 patients with osteochondrosis.

Median 25(OH)D concentrations were higher in all study subjects that carried the ff genotype (median $22.1 \mathrm{ng} / \mathrm{mL}$ ) than those with $F f$ (median $14.9 \mathrm{ng} / \mathrm{mL}$ ) and $F F$ genotypes (median $15.4 \mathrm{ng} / \mathrm{mL}$ ) $(+32 \%, p=0.031$; and $+30 \%, p=0.007$, respectively) (Supplementary Figure S1). However, this result was observed in healthy controls only (ff median $22.5 \mathrm{ng} / \mathrm{mL}$ versus $\mathrm{Ff} 13.4 \mathrm{ng} / \mathrm{mL},+41 \%, p=0.017$ and versus $F F 15.1 \mathrm{ng} / \mathrm{mL},+33 \%, p=0.004$ ), not in LBP patients (Figure 1).

\section{VDR FokI}

A
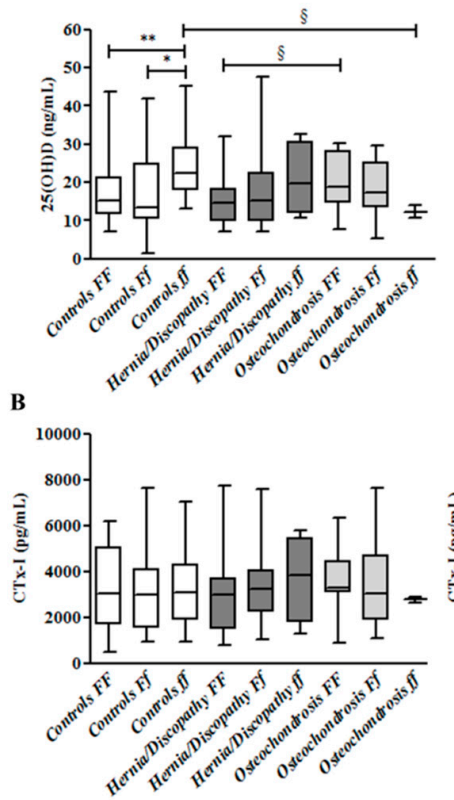

C

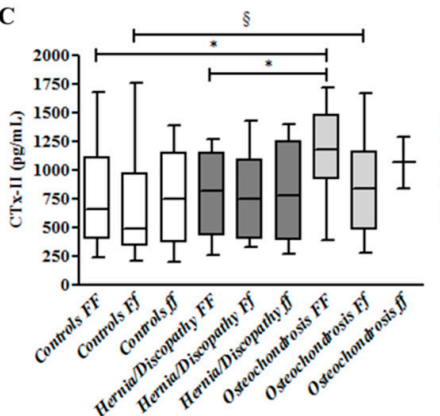

Alleles
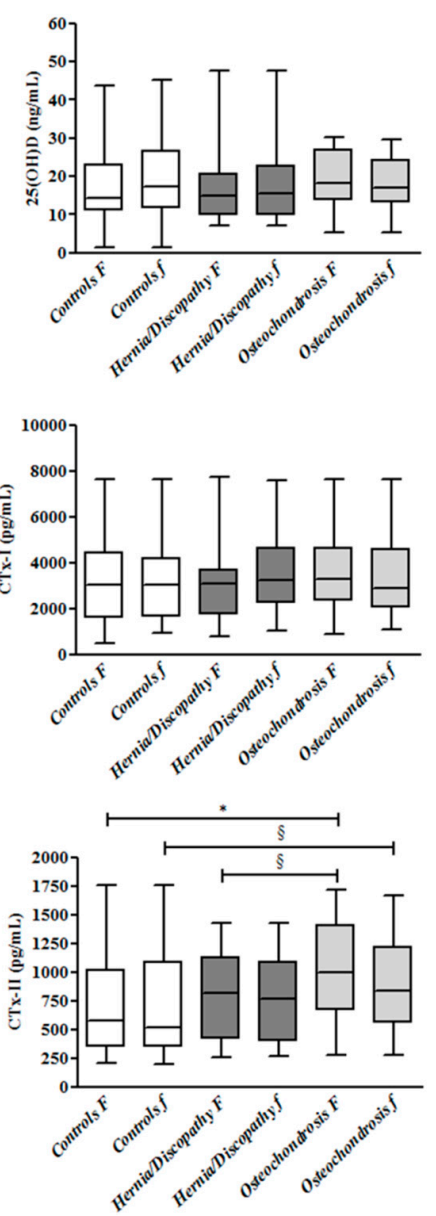

Figure 1. 25hydroxyvitamin D (25(OH)D) (A), cross-linked C-telopeptides of type I collagen (CTx-I) (B), and cross-linked C-telopeptides of type II collagen (CTx-II) (C) plasma concentrations in controls and in the subgroups of patients with hernia/discopathy and osteochondrosis, distributed according to FokI VDR genotypes/alleles. The box and whisker plots show the median, 25th, and 75th percentile (interquartile) (the box), and minimum and maximum value (the whiskers). ${ }^{*} p<0.05 .{ }^{* *} p<0.01$. $\S$ indicates a tendency. 
At variance, 25(OH)D concentrations did not differ significantly according to BsmI, ApaI, and TaqI genotypes and alleles when comparing all LBP cases versus healthy controls, and hernia/discopathy versus osteochondrosis patients (as shown in Figures S2-S4 and Figures 2-4).

\section{VDR BsmI}

A

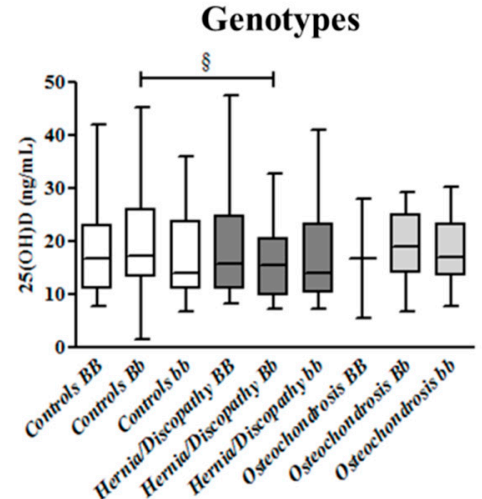

B

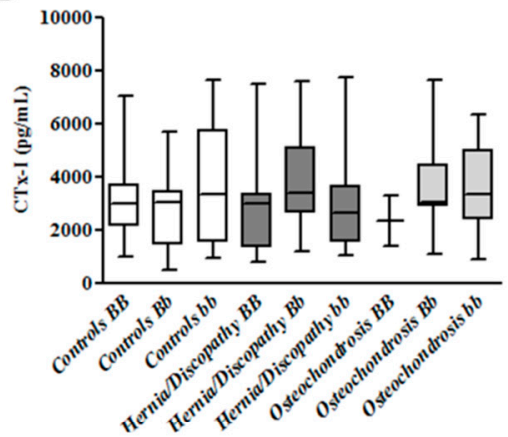

C

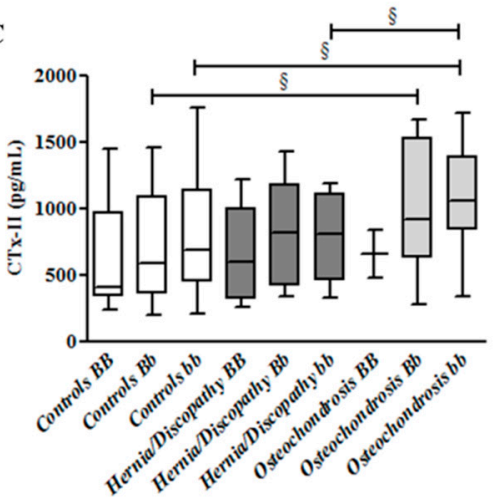

Alleles
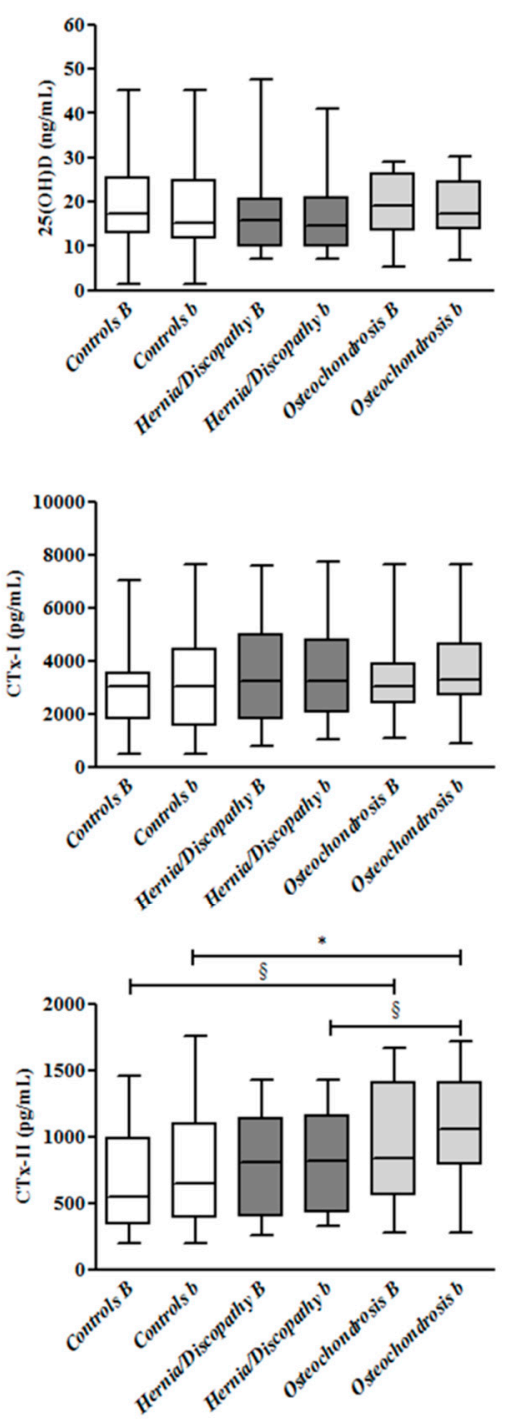

Figure 2. 25hydroxyvitamin D (25(OH)D) (A), cross-linked C-telopeptides of type I collagen (CTx-I) (B), and cross-linked C-telopeptides of type II collagen (CTx-II) (C) plasma concentrations in controls and in the subgroups of patients with hernia/discopathy and osteochondrosis, distributed according to BsmI VDR genotypes/alleles. The box and whisker plots show the median, 25th and 75th percentile (interquartile) (the box), and minimum and maximum value (the whiskers). ${ }^{*} p<0.05$. indicates a tendency. 


\section{VDR TaqI}

A

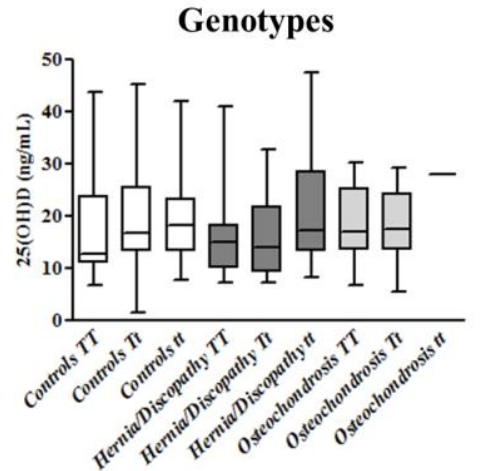

B
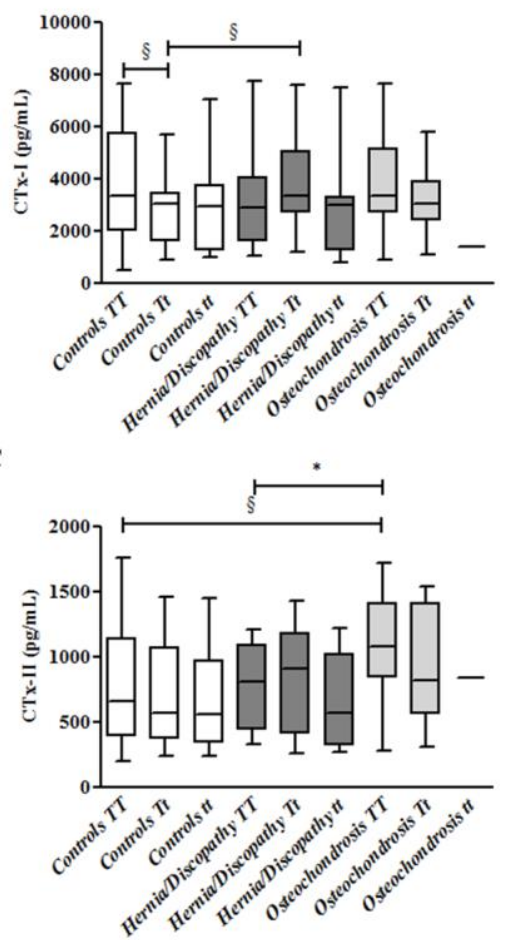

Alleles
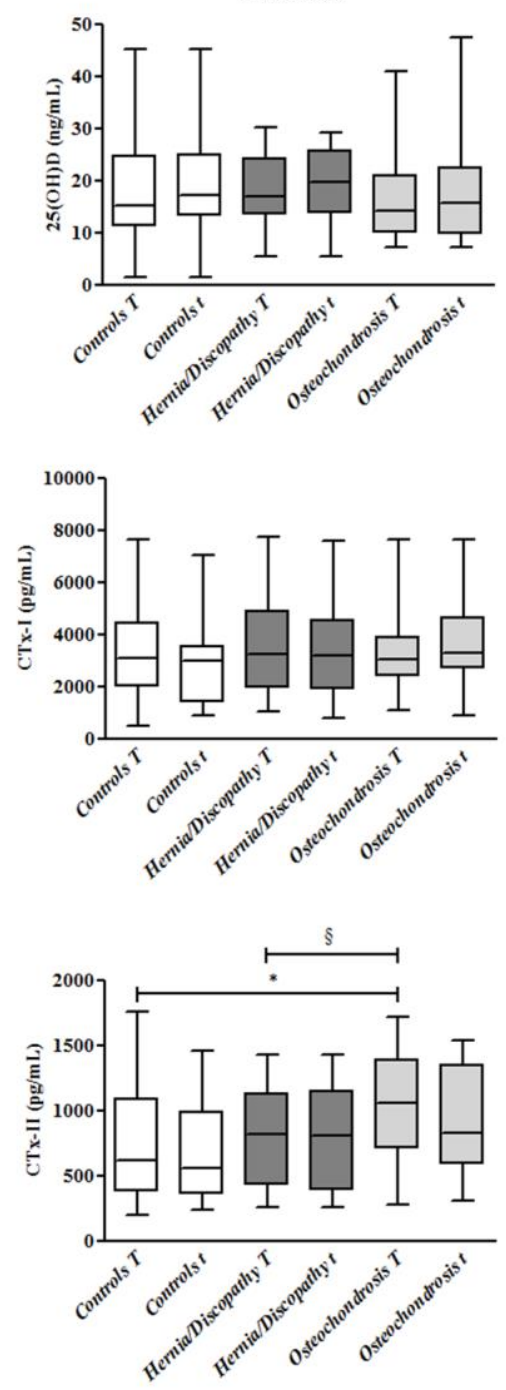

Figure 3. 25hydroxyvitamin D (25(OH)D) (A), cross-linked C-telopeptides of type I collagen (CTx-I) (B), and cross-linked C-telopeptides of type II collagen (CTx-II) (C) plasma concentrations in controls and in the subgroups of patients with hernia/discopathy and osteochondrosis, distributed according to TaqI VDR genotypes/alleles. The box and whisker plots show the median, 25th, and 75th percentile (interquartile) (the box), and minimum and maximum value (the whiskers). ${ }^{*} p<0.05 . \S$ indicates a tendency. 


\section{VDR ApaI}

A

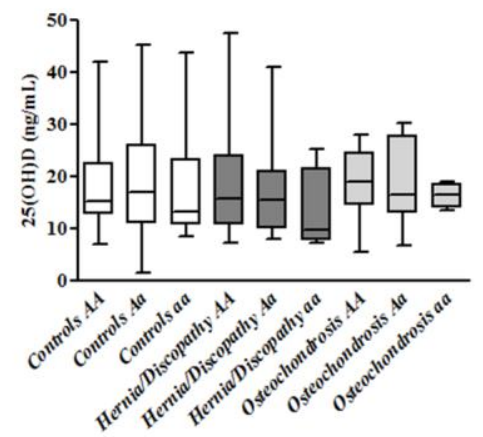

B

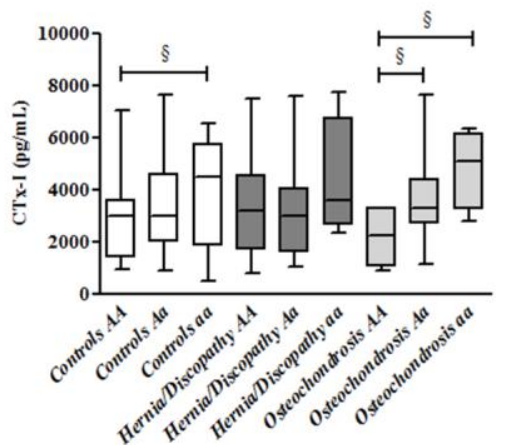

C

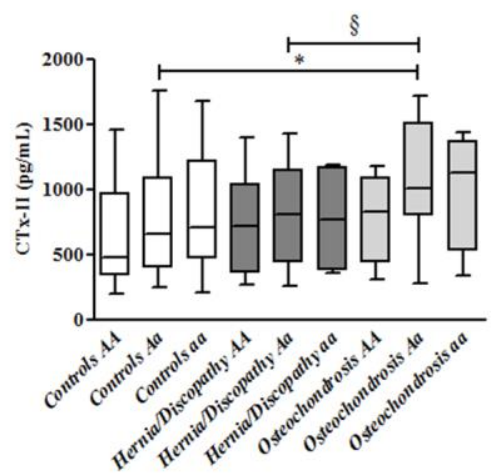

Alleles
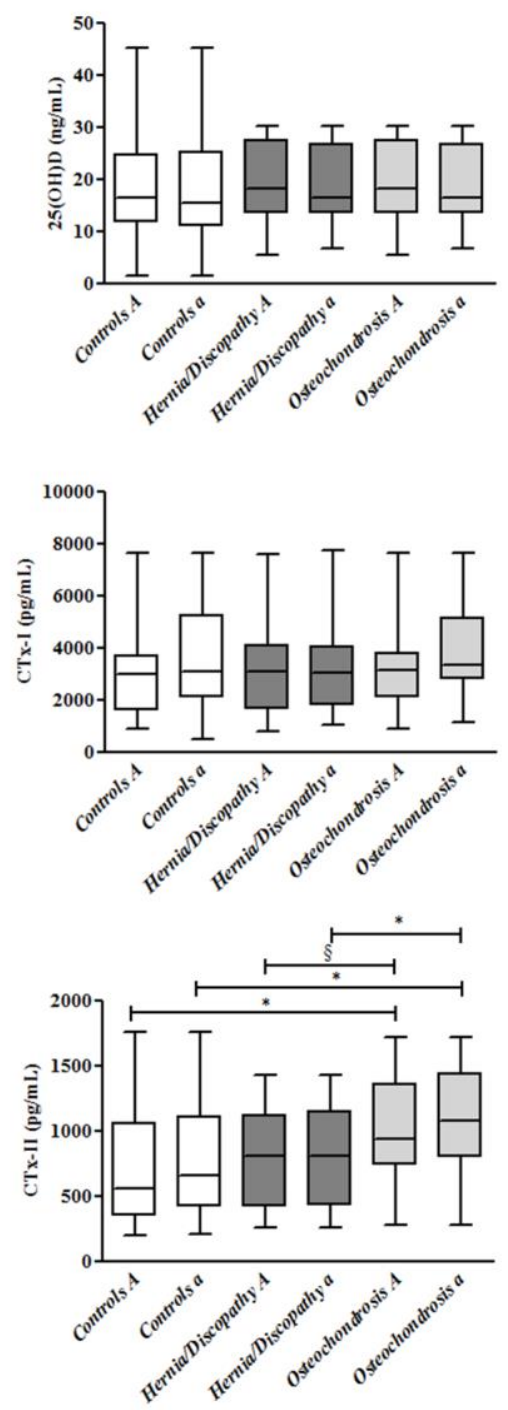

Figure 4. 25hydroxyvitamin D (25(OH)D) (A), cross-linked C-telopeptides of type I collagen (CTx-I) (B), and cross-linked C-telopeptides of type II collagen (CTx-II) (C) plasma concentrations in controls and in the subgroups of patients with hernia/discopathy and osteochondrosis, distributed according to ApaI VDR genotypes/alleles. The box and whisker plots show the median, 25th and 75th percentile (interquartile) (the box), and minimum and maximum value (the whiskers). ${ }^{*} p<0.05$. $\S$ indicates a tendency.

CTx-I concentrations did not differ, according to FokI polymorphism (as shown in Figure S1 and Figure 1).

Regarding CTx-II, among $F$ allele carriers, higher concentrations were observed in LBP patients (median $883 \mathrm{pg} / \mathrm{mL},+34 \%, p=0.025$ ) than in healthy controls (median $581 \mathrm{pg} / \mathrm{mL}$ ) (Supplementary Figure S1). However, the increase of CTx-II among F carriers was significant in patients with osteochondrosis (median $1000 \mathrm{pg} / \mathrm{mL},+42 \%, p=0.013$ ), but not in hernia/discopathy patients (median $813 \mathrm{pg} / \mathrm{mL}$ ) compared with healthy controls. $F$ carriers with osteochondrosis tended to have higher CTx-II than hernia/discopathy patients $(p=0.096)$. When considering FF genotype carriers, higher levels of CTx-II were observed in patients with osteochondrosis (median $1179 \mathrm{pg} / \mathrm{mL}$ ) 
than the healthy controls (median $655 \mathrm{pg} / \mathrm{mL})(+44 \%, p=0.017)$ and hernia/discopathy patients (median $820 \mathrm{pg} / \mathrm{mL})(+30 \%, p=0.013)$, as illustrated in Figure 1 .

\subsection{BsmI Polymorphism, and CTX-I and CTX-II Circulating Concentrations}

BsmI polymorphism did not affect 25(OH)D and CTx-I concentrations; however, some differences were found for CTx-II concentrations (Supplementary Figure S2 and Figure 2).

Among all study subjects $(+38 \%, p=0.017)$, and among LBP patients $(+36 \%, p=0.037), b b$ genotype carriers showed significantly higher CTx-II levels (median $839 \mathrm{pg} / \mathrm{mL}$ and median $947 \mathrm{pg} / \mathrm{mL}$, respectively) compared with $B B$ subjects (median $517 \mathrm{pg} / \mathrm{mL}$ and $600 \mathrm{pg} / \mathrm{mL}$ median, respectively) (Supplementary Figure S2). Among $b b$ genotype carriers, a tendency for higher CTx-II was observed in patients with osteochondrosis versus controls $(p=0.095)$ and patients with hernia/discopathy $(p=0.069)$ (Figure 2). Among subjects carrying the $b$ allele, increased concentrations of circulating CTx-II were found in LBP patients (median $929 \mathrm{pg} / \mathrm{mL},+30 \%, p=0.027$ ) compared with healthy controls (median $647 \mathrm{pg} / \mathrm{mL}$ ) (Supplementary Figure S2). Such findings were confirmed for osteochondrosis $b$ carriers (median $1056 \mathrm{pg} / \mathrm{mL},+39 \%, p=0.012$ ), but not for hernia/discopathy patients (median $813 \mathrm{pg} / \mathrm{mL}$ ) when compared with healthy controls (Figure 2).

Moreover, among $b$ allele carriers, CTx-II tended to be higher in patients with osteochondrosis than in hernia/discopathy patients $(p=0.093)$.

\subsection{TaqI Polymorphism, and CTX-I and CTX-II Circulating Concentrations}

Concerning CTx-I, slightly higher levels were found in TT than Tt carriers among controls $(p=0.059)$ (Figure 3$)$ and in $T t$ than $t t$ carriers among LBP cases $(p=0.086)$ (Supplementary Figure S3).

Significant increased concentrations of CTx-II were observed among $T$ carriers in LBP cases (median $910 \mathrm{pg} / \mathrm{mL},+32 \%, p=0.025$ ) compared with healthy controls (median $620 \mathrm{pg} / \mathrm{mL}$ ) (Supplementary Figure S3), and in osteochondrosis patients (median $1053 \mathrm{pg} / \mathrm{mL},+41 \%, p=0.013$ ) compared with healthy controls (Figure 3). As illustrated in Figure 3, among TT carriers, CTx-II concentrations were higher in patients with osteochondrosis (median $1081 \mathrm{pg} / \mathrm{mL},+26 \%, p=0.041$ ) than in patients with herniation/discopathy (median $803 \mathrm{pg} / \mathrm{mL}$ ).

\subsection{ApaI Polymorphism, and CTX-I and CTX-II Circulating Concentrations}

Significant increased concentrations of CTx-I were observed among the whole cohort of 158 subjects comparing $a a$ (median $4473 \mathrm{pg} / \mathrm{mL},+33 \%, p=0.038$ ) versus $A a$ (median $2983 \mathrm{pg} / \mathrm{mL}$ ) and $a a$ $(+32 \%, p=0.008)$ versus $A A$ (median $3022 \mathrm{pg} / \mathrm{mL}$ ) genotypes (Supplementary Figure S4). Among LBP cases, this difference was confirmed by comparing $a a$ (median $4184 \mathrm{pg} / \mathrm{mL},+24 \%, p=0.042$ ) with $A A$ genotype carriers (median $3181 \mathrm{pg} / \mathrm{mL}$ ) (Supplementary Figure S4).

A tendency for higher CTx-I was observed among healthy controls for aa (median $4473 \mathrm{pg} / \mathrm{mL}$ ) versus $A A$ (median $2999 \mathrm{pg} / \mathrm{mL}$ ) genotypes $(p=0.058)$, and in patients with osteochondrosis for $a a($ median $5090 \mathrm{pg} / \mathrm{mL})(p=0.067)$ and $A a($ median $3282 \mathrm{pg} / \mathrm{mL})(p=0.059)$ versus $A A$ (median $2211 \mathrm{pg} / \mathrm{mL})$ genotypes.

A significant increase of CTx-II was observed in all study subjects upon comparing $A a$ (median $839 \mathrm{pg} / \mathrm{mL},+33 \%, p=0.030$ ) and $A A$ (median $562 \mathrm{pg} / \mathrm{mL}$ ) genotypes. Among $A$ allele carriers, CTx-II had higher concentrations in LBP cases (median $838 \mathrm{pg} / \mathrm{mL},+34 \%, p=0.023$ ) than in healthy controls (median 554 pg/mL) (Supplementary Figure S4).

As illustrated in Figure 4, among $a$ allele carriers, patients with osteochondrosis (median 1081 $\mathrm{pg} / \mathrm{mL}$ ) had higher CTx-II concentrations than the healthy controls (median $661 \mathrm{pg} / \mathrm{mL})(+39 \%$, $p=0.015)$ and the hernia/discopathy patients (median $809 \mathrm{pg} / \mathrm{mL})(+25 \%, p=0.048)$. However, also among $A$ carriers, osteochondrosis patients (median $933 \mathrm{pg} / \mathrm{mL},+41 \%, p=0.014$ ) had higher CTx-II concentrations than healthy controls (median $554 \mathrm{pg} / \mathrm{mL}$ ). 
Finally, among $A a$ genotype carriers, patients with osteochondrosis (median $1003 \mathrm{pg} / \mathrm{mL},+35 \%$, $p=0.017$ ) showed higher CTx-II levels in comparison with healthy controls (median $654 \mathrm{pg} / \mathrm{mL}$ ) (Figure 4).

\subsection{Summary for the Association between CTX-II Circulating Concentrations and VDR Polymorphisms}

The differences in CTx-II plasma concentrations in the healthy controls and patients with osteochondrosis according to VDR genotypes/alleles are summarized in Table 2. These results are matched with data regarding the association of the same VDR polymorphisms in a larger Italian cohort of subjects comprising a total of 50 patients with osteochondrosis (40 males and 10 females) and 252 healthy controls (127 males and 125 females) and including subjects of the current investigation [1,2,27]. The presence of $b b, A a$, and TT genotypes, and $F$ and $T$ alleles, are associated with the risk to develop osteochondrosis in the large cohort. The same genetic traits showed higher CTx-II circulating levels in the present study.

Table 2. Differences in cross-linked C-telopeptides of type II collagen circulating concentrations between patients with osteochondrosis and healthy controls, according to VDR genotypes/alleles.

\begin{tabular}{cccccc}
\hline VDR Polymorphisms & \multicolumn{3}{c}{ Genotypes } & \multicolumn{3}{c}{ Alleles } \\
\hline FokI & $F F^{*}$ & $F f^{\S}$ & $f f^{\#}$ & $\boldsymbol{F}^{*,}$ & $f^{\S}$ \\
BsmI & $B B$ & $B b^{\S}$ & $\boldsymbol{b} \boldsymbol{b}^{\S, \wedge}$ & $B \S$ & $b^{*}$ \\
TaqI & $T T^{\S, \wedge}$ & $T t$ & $t t^{\#}$ & $\boldsymbol{T}^{* \wedge}$ & $t^{\#}$ \\
ApaI & $A A^{\#}$ & $A \boldsymbol{a}^{*, \wedge}$ & $a a$ & $A^{*}$ & $a^{*}$ \\
\hline
\end{tabular}

* $p<0.05$ significant higher levels of plasma CTx-II in osteochondrosis patients, $\$$ tendency of higher levels of plasma CTx-II in osteochondrosis patients. ^ risky and \# protective genotypes and alleles observed in a larger cohort of Italian subjects $[1,2,27]$ composed by 50 patients with osteochondrosis (with or without hernia or discopathy) and 252 healthy controls. The genotypes and alleles that are significantly relevant for patients with osteochondrosis compared with the healthy controls are indicated in bold.

\section{Discussion}

The influence of human DNA polymorphisms on the phenotype and on several biomarkers is intensively studied in order to develop a personalized medical approach to several pathologies [29]. Accumulating evidence points to a nutrigenomic approach and, in this context, vitamin D is increasingly studied [30]. Recently, a number of studies specifically evaluated VDR polymorphisms and LBP [25].

In this case control study, a cohort of Italian males affected by two types of lumbar disc degeneration-related spine pathologies was compared with a matched cohort of healthy subjects in term of presence of four specific VDR genotypes, blood vitamin $\mathrm{D}$, and the concentration of two catabolic osteocartilaginous markers. The biochemical data were analyzed according to specific $V D R$ genetic features to isolate the influence of genetic variants on the development of pathological conditions and systemic biochemical alterations.

Patients with lumbar vertebral osteochondrosis emerged from the current and previous research $[1,2,27]$ as a LBP group of patients with peculiar characteristics. Consistently with frequencies of VDR polymorphisms observed in a previously published larger study of Italian LBP patients [27], the $T T$ and $A a$ genotypes, and the $T$ and $b$ alleles were more frequently found in patients with osteochondrosis than in healthy controls. Furthermore, a previous study [21] performed on the same subjects showed that osteochondrosis patients showed higher plasma CTx-II concentrations levels (median $1000 \mathrm{pg} / \mathrm{mL}$ ) than healthy controls (median $604 \mathrm{pg} / \mathrm{mL}$ ), and higher levels of this marker in comparison with hernia/discopathies patients without osteochondrosis (median $805 \mathrm{pg} / \mathrm{mL}$ ), which suggests that osteochondrosis strongly associates with increased cartilaginous catabolism [21].

The main aim of this study was to test the hypothesis of whether specific VDR polymorphisms affect the circulating concentrations of vitamin $\mathrm{D}$ and markers of collagen degradation. 
Concerning plasma $25(\mathrm{OH}) \mathrm{D}$ concentrations and VDR polymorphisms, our study showed that $f f$ carriers had higher $25(\mathrm{OH}) \mathrm{D}$ than $F F$ and $F f$ carriers among all study subjects and among healthy subjects. Circulating levels of $25(\mathrm{OH}) \mathrm{D}$ are the result of the fine tuning of several counteracting mechanisms and are considered to reflect vitamin D body stores [31]. One hypothesis could be that in individuals with the minor $f f$ genotype producing a VDR receptor that is three amino acids longer and less active, such balancing requires higher levels of circulating vitamin D [32] in healthy individuals in order to maintain homeostasis.

We found no evidence for $V D R$ polymorphisms acting as major modifiers of the association between $25(\mathrm{OH}) \mathrm{D}$ concentrations and hernia/discopathy or osteochondrosis. Our data partially concurs with that of Marques Vidigal V et al. [33].

To our knowledge, our study was the first to investigate the relationship between VDR polymorphisms and plasma concentrations of CTx-I and CTx-II. The interesting finding regarding the functional FokI VDR polymorphism was the observation of higher CTx-II levels in F allele carriers osteochondrosis patients compared with healthy controls. Among FF carriers, CTx-II reached almost doubled median values in osteochondrosis patients $(1179 \mathrm{pg} / \mathrm{mL})$ compared with healthy controls $(655 \mathrm{pg} / \mathrm{mL})$, with hernia/discopathy patients showing intermediate values $(820 \mathrm{pg} / \mathrm{mL})$. No previous study examined such relationships. We previously showed that vitamin $\mathrm{D}$ in vitro inhibits the synthesis of type I and II collagens in the disc cells [24]. It is plausible that among patients with osteochondrosis carriage, who are affected by a higher cartilage catabolism, the $F$ allele implies a higher transcriptional activity of the VDR, and results in a pronounced inhibition of resident cells that potentially enhances the development or progression of the pathology.

In our study, CTx-II concentrations were also affected by three silent polymorphisms: BsmI, ApaI, and TaqI, which are located near the $3^{\prime}$ terminus (intron 8/exon 9) of the VDR.

The association between CTx-II levels and the VDR BsmI polymorphism showed some intriguing results. Among $b$ allele carriers, osteochondrosis patients showed almost double the CTx-II of healthy controls. Moreover, among all LBP patients, $b b$ carriers had almost double the CTx-II of $B B$ carriers. However, the similar trend observed among subgroups of patients was not statistically significant. Further enlarged studies are warranted to assess the role of the $b$ allele and the $b b$ genotype in promoting type 2 collagen degradation, and consequently increasing the risk for osteochondrosis [27].

A higher cartilage catabolism (as assessed by CTx-II) was also observed in osteochondrosis patients with $T$ allele and $T T$ genotypes than in the healthy controls and hernia/discopathy patients. These data reinforce the hypothesis that the $T$ allele promotes collagen catabolism and consequently osteochondrosis, as already observed in a population-based twin cohort study on Finnish males [34].

Finally, exploring the relationships between ApaI polymorphism and CTx-II, the group with the highest concentrations over $1000 \mathrm{pg} / \mathrm{mL}$ were observed in osteochondrosis patients carriers of the $a$ allele and $a a$ genotype, whereas the lowest concentrations around $500 \mathrm{pg} / \mathrm{mL}$ were found in healthy subjects carriers of the $A$ allele and $A A$ genotype. However, among both $A$ and $a$ alleles carriers, osteochondrosis patients had higher CTx-II than the healthy controls, which reflects the general CTx-II increase in osteochondrosis patients compared with healthy controls [21].

Furthermore, the $A a$ genotype had higher CTx-II than $A A$ carriers among all of the study subjects. It is to note that this heterozygous genotype was already known to be associated with osteochondrosis [27].

In summary, regarding the association between CTx-II and VDR polymorphisms in patients with osteochondrosis, we observed the presence of higher CTx-II circulating levels in patients with $b b, A a$, and TT genotypes, and $F$ and $T$ alleles, in comparison with the healthy controls. These genotypes and alleles were already observed to be associated with the risk to develop osteochondrosis in a larger cohort of Italian subjects $[1,2,27]$.

Concerning CTx-I, which is considered a marker of bone-cartilaginous catabolism, we observed a trend for increased CTx-I levels in TT versus Tt controls, and Tt versus $t t$ cases, which suggested an increase in bone catabolism in subjects carrying the $T$ allele. The opposite trend was observed for 
the $25(\mathrm{OH}) \mathrm{D}$, which confirmed the previously reported inverse correlation between the vitamin $\mathrm{D}$ hormone and CTx-I levels [21].

Considering VDR ApaI polymorphism, the aa genotype seemed to be associated with an increased bone catabolism. Of note, a recent immunohistochemical study performed in human melanoma excised cells observed lower VDR protein expression in homozygous aa carries [35], which suggests that the aa genotype can negatively modulate tissue expression of VDR, and thus affect vitamin D actions. Future studies will be necessary to better assess the role of ApaI polymorphism in collagen degradation and in human diseases in general.

In summary, the associations between the specific $V D R$ genetic variants and bone/cartilaginous catabolic markers observed in this study confirm the peculiarity of the vertebral osteochondrosis with respect to other lumbar discopathies.

Since osteochondrosis involves both cartilage and bone metabolism showing particular neoformations such as osteophytes, and since the pleiotropic vitamin D has a role in the metabolic control of both types of these tissues, it is likely that modifications in the hormone's activity can have a role in the pathophysiology of this condition.

In this context, the only study evaluating the role of vitamin $\mathrm{D}$ in the osteochondrosis was performed on a swine model. The authors suggested that the dietary supplementation of 25(OH)D can reduce the development of this condition in pigs through VDR activity enhancement, and speculated that the hormone can reduce the IL- $1 \beta$ and TNF- $\alpha$ and promote TGF- $\beta$ and IGF- 1 release, favoring the cartilage homeostasis [36].

The regulatory effects of VDR on the human genome are much more complex than previously thought [37]. Of interest, a recent genome-wide study by Singh et al. [38] found a genetic link between VDR and NF-kB, a factor that in turn modulates pro-inflammatory cytokines [39].

Our study has some limitations. The main limitation is the limited number of subjects, especially when LBP patients were divided into patient subgroups. The strengths of our study are the well-characterized subgroups of LBP patients and detailed lifestyle, genetic, and biochemical data.

In conclusion, the present study highlighted for the first time that $V D R$ polymorphisms can affect blood CTx-I, CTx-II, and vitamin D levels both in LBP patients and healthy subjects. Our findings suggest that further investigations on the genotype-related functional response of the disc cells to vitamin $\mathrm{D}$ will be the next steps toward a deeper knowledge of the pathophysiology of disc diseases. Moreover, our results indicate that the focus should be directed to specific subgroups of LBP patients, particularly on those with osteochondrosis, as this condition appears more influenced by the different specific $V D R$ polymorphisms.

Very recent research revealed that the influence of variations in DNA sequences on the phenotype is strongly filtered by regulatory networks at higher levels, including cells, tissues, organs, and systems. Thus, understanding better the filtering by regulatory networks at tissue levels may improve our knowledge on physiological and pathological pathways [40].

\section{Materials and Methods}

\subsection{Subjects and Clinical Evaluation}

This protocol named GENODISC01 was approved by the Institutional Ethical Review Board ASL Città di Milano, and this study was conducted in accordance with the Helsinki Declaration (approval date 29 January 2009; amendment for case cohort enlargement and for healthy controls inclusion, approval 12 December 2011).

Seventy-nine white male patients with LBP and lumbar disc herniation, and/or discopathies and/or osteochondrosis, confirmed by magnetic resonance imaging (MRI) performed by a 1.5 Tesla scanner (Avanto, Siemens, Erlangen, Germany, EU) and 79 asymptomatic sex-, age- and BMI-matched healthy subjects were enrolled at the IRCCS Galeazzi Orthopaedic Institute during the European GenoDisc Project, according to the inclusion and exclusion criteria previously described [21]. Briefly, 
LBP patients and healthy controls filled out a detailed questionnaire comprising clinical and lifestyle data (including weight and height). All study subjects attested that they were not affected by concomitant pathologies such as cervical discopathies, scoliosis, hip, knee and hand osteoarthritis, osteoporosis, fibromyalgia, tumors, lupus erythematosus, and rheumatoid arthritis. Healthy controls had no episodes of LBP longer than one day ever in their life. Diagnosis was performed on the bases of the clinical features by a single senior spine surgeon. Disc herniation was diagnosed in the presence of disc material protrusion/extrusion beyond the posterior margins of the adjacent vertebral bodies, and was often associated with discopathies (degenerative changes of the IVD) and/or osteochondrosis. Osteochondrosis was diagnosed in the presence of disc space narrowing, subchondral sclerosis, wavy endplates, osteophytes, and Schmorl's node [1].

\subsection{Samples Collection}

Blood samples were collected from the antecubital vein in $\mathrm{K}_{2}$ EDTA containing tubes (Becton-Dickinson, Franklin Lakes, NJ, USA), centrifuged at $1200 \times \mathrm{g}$ for $10 \mathrm{~min}$ at $4{ }^{\circ} \mathrm{C}$, and plasma aliquots and pellet blood cells were stored at $-80^{\circ} \mathrm{C}$ until assayed.

\subsection{Analysis of Genotypes}

The determination of SNP VDR-FokI (C > T), VDR-BsmI (G > A), VDR-ApaI (T > G), and VDR-TaqI $(T>C)$ was performed, as previously described $[1,27,41]$. Genomic DNA was extracted from blood cells according to the procedure of the DNeasy Midi kit (Qiagen, Duesseldorf, Germany). FokI, BsmI, ApaI, and TaqI polymorphisms of VDR were detected through polymerase chain reaction and restriction fragment length polymorphism (PCR-RFLP) methods using appropriate primers, as previously described $[1,27]$. Capital letters $F, B, A$, and $T$ indicated alleles according to the absence of the restriction site for the FokI, BsmI, ApaI, and TaqI enzymes, respectively, whereas the lower letters $f, b, a$, and $t$ denoted alleles according to the presence of the respective restriction sites. Each $V D R$ polymorphism of FokI, BsmI, ApaI, and TaqI was in Hardy-Weinberg equilibrium (HWE). As expected, FokI SNP was not in linkage disequilibrium (LD) with the other three VDR-SNPs. BsmI was in LD with ApaI and TaqI, and ApaI was in LD with TaqI [27].

\subsection{Assessment of Circulating Levels of $25(\mathrm{OH}) \mathrm{D}, \mathrm{CT} x$-I and CTx-II}

The competitive immunoassay 25-Hydroxy-vitamin D total ELISA (Tecan Group Ltd., Männedorf, Switzerland), cross-linked C-telopeptide fragments of type I collagen (CTx-I) and of type II (CTx-II) collagen ELISAs (D.B.A. Italia s.r.l., Milan, Italy) were used to determine the $25(\mathrm{OH}) \mathrm{D}\left(\mathrm{D}_{2}\right.$ and $\left.\mathrm{D}_{3}\right)$, CTx-I and CTx-II concentrations in plasma.

All the ELISA kits were used following the manufacturer's indications.

For $25(\mathrm{OH}) \mathrm{D}$, the lower limit of detection ( $\mathrm{LoD})$ was $2.81 \mathrm{ng} / \mathrm{mL}$, while the intra-assay $(\mathrm{CVw})$ and inter-assay $(\mathrm{CVb})$ variations were $\leq 7.8 \%$ and $\leq 9.2 \%$, respectively.

The lower LoD was less than $53.4 \mathrm{pg} / \mathrm{mL}$ for CTx-I and $52.3 \mathrm{pg} / \mathrm{mL}$ for CTx-II. Variability CVw and $\mathrm{CVb}$ for both the assays were $<10 \%$ and $<12 \%$, respectively.

Differences were considered significant for $25(\mathrm{OH}) \mathrm{D}$ when higher than the $6.9 \%$, taking into account the within-person biological variation $\left(\mathrm{CV}_{\mathrm{W}}\right)$ [42]. No data concerning the biological variation of CTx-I and CTx-II was found in the literature.

Despite CTx-II being normally measured in urine as the quantification of this marker, it is also possible in serum or plasma [21]. The approved protocol for this study enabled the collection of whole blood in $\mathrm{K}_{2}$ EDTA-containing tubes, and this accounted for the CTx-II measurement in plasma.

\subsection{Statistical Analysis}

The normality of data distribution was assessed using Kolmogorov-Smirnov and Shapiro-Wilk tests. 
Plasma concentration data were not normally distributed, and were reported by box plots indicating the median, 25th and 75th percentile (interquartile, IQR), and minimum and maximum values.

Odds ratios (ORs) and 95\% confidence intervals (CIs) were calculated to set the association between alleles or genotypes, and the risk of spine pathologies in LBP cases and controls.

The comparisons of continuous variables were performed by the means of the Student's $t$ and Mann Whitney tests as appropriate. Two-sided significance level was held at 0.05 , and $p$ values $\leq 0.10$ were considered as a tendency to be significant.

Statistical software used was GraphPad Prism version 5.00 (GraphPad software, La Jolla, CA, USA).

Supplementary Materials: Supplementary materials can be found at www.mdpi.com/1422-0067/18/10/2073/s1.

Acknowledgments: Financial support: This work has been partially supported by European Community's Seventh Framework Programme (FP7, 2007-2013 under Grant Agreement No. HEALTHF2-2008-201626) and by the Italian Ministry of Health. The funder organizations had no role in study design, data collection and analysis, decision to publish, or preparation of the manuscript.

Author Contributions: Sabina Cauci: genetic experiments set up and supervision, paper writing and final revision. Marco Viganò: experiments performing, data analysis, paper writing. Laura de Girolamo: paper revision. Paola De Luca: paper revision. Carlotta Perucca Orfei: paper revision. Giuseppe Banfi: paper revision. Giovanni Lombardi: patients recruitment, clinical data entry. Marco Brayda-Bruno: clinical assessment, patients recruitment, paper revision. Alessandra Colombini: study conception, experiments performing, data analysis, paper writing.

Conflicts of Interest: The authors declare no conflict of interest.

\section{References}

1. Colombini, A.; Brayda-Bruno, M.; Lombardi, G.; Croiset, S.J.; Vrech, V.; Maione, V.; Banfi, G.; Cauci, S. FokI polymorphism in the vitamin $\mathrm{D}$ receptor gene (VDR) and its association with lumbar spine pathologies in the Italian population: A case-control study. PLoS ONE 2014, 9, e97027. [CrossRef] [PubMed]

2. Colombini, A.; Brayda-Bruno, M.; Ferino, L.; Lombardi, G.; Maione, V.; Banfi, G.; Cauci, S. Gender differences in the VDR-FokI polymorphism and conventional non-genetic risk factors in association with lumbar spine pathologies in an Italian case-control study. Int. J. Mol. Sci. 2015, 16, 3722-3739. [CrossRef] [PubMed]

3. Aufdermaur, M. Juvenile kyphosis (Scheuermann's disease): Radiography, histology, and pathogenesis. Clin. Orthop. Relat. Res. 1981, 154, 166-174.

4. Scheuermann, H.W. The classic: Kyphosis dorsalis juvenilis. Clin. Orthop. Relat. Res. 1977, 128, 5-7. [CrossRef]

5. Lesoin, F.; Leys, D.; Rousseaux, M.; Dubois, F.; Villette, L.; Pruvo, J.P.; Petit, H.; Jomin, M. Thoracic disk herniation and Scheuermann's disease. Eur. Neurol. 1987, 26, 145-152. [CrossRef] [PubMed]

6. Blumenthal, S.L.; Roach, J.; Herring, J.A. Lumbar Scheuermann's. A clinical series and classification. Spine 1987, 12, 929-932. [CrossRef] [PubMed]

7. Tallroth, K.; Schlenzka, D. Spinal stenosis subsequent to juvenile lumbar osteochondrosis. Skelet. Radiol. 1990, 19, 203-205. [CrossRef]

8. Trotta, A.; Corrado, A.; Soragnese, M.F.; Santoro, N.; Cantatore, F.P. Adult Scheuermann's disease as cause of mechanic dorsalgia. Reumatismo 2008, 60, 14-21. [CrossRef] [PubMed]

9. Tribus, C.B. Scheuermann's kyphosis in adolescents and adults: Diagnosis and management. J. Am. Acad. Orthop. Surg. 1998, 6, 36-43. [CrossRef] [PubMed]

10. McFadden, K.D.; Taylor, J.R. End-plate lesions of the lumbar spine. Spine 1989, 14, 867-869. [CrossRef] [PubMed]

11. Lowe, T.G. Scheuermann disease. J. Bone Jt. Surg. Am. Vol. 1990, 72, 940-945. [CrossRef]

12. Liu, N.; Guo, X.; Chen, Z.; Qi, Q.; Li, W.; Guo, Z.; Zeng, Y.; Sun, C.; Liu, Z. Radiological signs of Scheuermann disease and low back pain: Retrospective categorization of 188 hospital staff members with 6-year follow-up. Spine 2014, 39, 1666-1675. [CrossRef] [PubMed]

13. Stoddard, A.; Osborn, J.F. Scheuermann's disease or spinal osteochondrosis: Its frequency and relationship with spondylosis. J. Bone Jt. Surg. Br. Vol. 1979, 61, 56-58. 
14. Aufdermaur, M.; Spycher, M. Pathogenesis of osteochondrosis juvenilis Scheuermann. J. Orthop. Res. Off. Publ. Orthop. Res. Soc. 1986, 4, 452-457. [CrossRef] [PubMed]

15. Dommisse, G.F. The vulnerable, rapidly growing thoracic spine of the adolescent. S. Afr. Med. J. S.-Afr. Tydskr. Geneeskd. 1990, 78, 211-213.

16. Graat, H.C.; van Rhijn, L.W.; Schrander-Stumpel, C.T.; van Ooij, A. Classical Scheuermann disease in male monozygotic twins: Further support for the genetic etiology hypothesis. Spine 2002, 27, E485-E487. [CrossRef] [PubMed]

17. Damborg, F.; Engell, V.; Andersen, M.; Kyvik, K.O.; Thomsen, K. Prevalence, concordance, and heritability of Scheuermann kyphosis based on a study of twins. J. Bone Jt. Surg. Am. Vol. 2006, 88, 2133-2136.

18. Halal, F.; Gledhill, R.B.; Fraser, C. Dominant inheritance of Scheuermann's juvenile kyphosis. Am. J. Dis. Child. 1978, 132, 1105-1107. [CrossRef] [PubMed]

19. McKenzie, L.; Sillence, D. Familial Scheuermann disease: A genetic and linkage study. J. Med. Genet. 1992, 29, 41-45. [CrossRef] [PubMed]

20. Colombini, A.; Cauci, S.; Lombardi, G.; Lanteri, P.; Croiset, S.; Brayda-Bruno, M.; Banfi, G. Relationship between vitamin D receptor gene (VDR) polymorphisms, vitamin D status, osteoarthritis and intervertebral disc degeneration. J. Steroid Biochem. Mol. Biol. 2013, 138, 24-40. [CrossRef] [PubMed]

21. Brayda-Bruno, M.; Vigano, M.; Cauci, S.; Vitale, J.A.; de Girolamo, L.; De Luca, P.; Lombardi, G.; Banfi, G.; Colombini, A. Plasma vitamin D and osteo-cartilaginous markers in Italian males affected by intervertebral disc degeneration: Focus on seasonal and pathological trend of type II collagen degradation. Clin. Chim. Acta Int. J. Clin. Chem. 2017, 471, 87-93. [CrossRef] [PubMed]

22. Amizuka, N.; Ozawa, H. Intracellular localization and translocation of 1 alpha, 25-dihydroxyvitamin D3 receptor in osteoblasts. Arch. Histol. Cytol. 1992, 55, 77-88. [CrossRef] [PubMed]

23. Gruber, H.E.; Hoelscher, G.; Ingram, J.A.; Chow, Y.; Loeffler, B.; Hanley, E.N., Jr. 1,25(OH)2-vitamin D3 inhibits proliferation and decreases production of monocyte chemoattractant protein-1, thrombopoietin, VEGF, and angiogenin by human annulus cells in vitro. Spine 2008, 33, 755-765. [CrossRef] [PubMed]

24. Colombini, A.; Lanteri, P.; Lombardi, G.; Grasso, D.; Recordati, C.; Lovi, A.; Banfi, G.; Bassani, R.; Brayda-Bruno, M. Metabolic effects of vitamin D active metabolites in monolayer and micromass cultures of nucleus pulposus and annulus fibrosus cells isolated from human intervertebral disc. Int. J. Biochem. Cell Biol. 2012, 44, 1019-1030. [CrossRef] [PubMed]

25. Chen, L.; Zhao, S.; Niu, F.; Bi, G.B. Association between vitamin D receptor gene polymorphisms and intervertebral disc degeneration: A meta-analysis. J. Orthop. Sci. 2017, 22, 184-189. [CrossRef] [PubMed]

26. Jiang, H.; Qin, Z.L.; Zong, S.H.; He, M.L.; Zhan, X.L.; Xiao, Z.M.; Wei, Q.J. Vitamin D receptor gene polymorphisms and lumbar disc degeneration: A systematic review and meta-analysis. Eur. Spine J. 2017, 26, 267-277. [CrossRef] [PubMed]

27. Colombini, A.; Brayda-Bruno, M.; Lombardi, G.; Croiset, S.J.; Ceriani, C.; Buligan, C.; Barbina, M.; Banfi, G.; Cauci, S. BsmI, ApaI and TaqI Polymorphisms in the Vitamin D Receptor Gene (VDR) and Association with Lumbar Spine Pathologies: An Italian Case-Control Study. PLoS ONE 2016, 11, e0155004. [CrossRef] [PubMed]

28. Colombini, A.; Lombardi, G.; Corsi, M.M.; Banfi, G. Pathophysiology of the human intervertebral disc. Int. J. Biochem. Cell Biol. 2008, 40, 837-842. [CrossRef] [PubMed]

29. Collins, F.S.; Varmus, H. A new initiative on precision medicine. N. Engl. J. Med. 2015, 372, $793-795$. [CrossRef] [PubMed]

30. Rescigno, T.; Micolucci, L.; Tecce, M.F.; Capasso, A. Bioactive nutrients and nutrigenomics in age-related diseases. Molecules 2017, 22, 105. [CrossRef] [PubMed]

31. Lanteri, P.; Lombardi, G.; Colombini, A.; Banfi, G. Vitamin D in exercise: Physiologic and analytical concerns. Clin. Chim. Acta Int. J. Clin. Chem. 2013, 415, 45-53. [CrossRef] [PubMed]

32. Uitterlinden, A.G.; Fang, Y.; Van Meurs, J.B.; Pols, H.A.; Van Leeuwen, J.P. Genetics and biology of vitamin D receptor polymorphisms. Gene 2004, 338, 143-156. [CrossRef] [PubMed]

33. Marques, V.V.; Aguiar, J.P.N.; Donizetti, S.T.; de Oliveira, J.; Marques, P.C.A.; Vitor, F.A.; Manoukian, F.N. Genetic polymorphisms of vitamin D metabolism genes and serum level of vitamin D in colorectal cancer. Int. J. Biol. Markers 2017. [CrossRef] [PubMed] 
34. Videman, T.; Gibbons, L.E.; Battie, M.C.; Maravilla, K.; Vanninen, E.; Leppavuori, J.; Kaprio, J.; Peltonen, L. The relative roles of intragenic polymorphisms of the vitamin $\mathrm{d}$ receptor gene in lumbar spine degeneration and bone density. Spine 2001, 26, E7-E12. [CrossRef] [PubMed]

35. La Marra, F.; Stinco, G.; Buligan, C.; Chiriaco, G.; Serraino, D.; Di Loreto, C.; Cauci, S. Immunohistochemical evaluation of vitamin D receptor (VDR) expression in cutaneous melanoma tissues and four VDR gene polymorphisms. Cancer Biol. Med. 2017, 14, 162-175. [PubMed]

36. Sugiyama, T.; Kusuhara, S.; Chung, T.K.; Yonekura, H.; Azem, E.; Hayakawa, T. Effects of 25-hydroxycholecalciferol on the development of osteochondrosis in swine. Anim. Sci. J. 2013, 84, 341-349. [CrossRef] [PubMed]

37. Long, M.D.; Campbell, M.J. Integrative genomic approaches to dissect clinically-significant relationships between the VDR cistrome and gene expression in primary colon cancer. J. Steroid Biochem. Mol. Biol. 2017, 173, 130-138. [CrossRef] [PubMed]

38. Singh, P.K.; van den Berg, P.R.; Long, M.D.; Vreugdenhil, A.; Grieshober, L.; Ochs-Balcom, H.M.; Wang, J.; Delcambre, S.; Heikkinen, S.; Carlberg, C.; et al. Integration of VDR genome wide binding and GWAS genetic variation data reveals co-occurrence of VDR and NF-kappaB binding that is linked to immune phenotypes. BMC Genom. 2017, 18, 132. [CrossRef] [PubMed]

39. Lawrence, T. The nuclear factor NF-kappaB pathway in inflammation. Cold Spring Harb. Perspect. Biol. 2009, 1, a001651. [CrossRef] [PubMed]

40. Soto, A.M.; Longo, G.; Noble, D. Preface to from the century of the genome to the century of the organism: New theoretical approaches. Prog. Biophys. Mol. Biol. 2016, 122, 1-3. [CrossRef] [PubMed]

41. Pani, M.A.; Knapp, M.; Donner, H.; Braun, J.; Baur, M.P.; Usadel, K.H.; Badenhoop, K. Vitamin D receptor allele combinations influence genetic susceptibility to type 1 diabetes in Germans. Diabetes 2000, 49, 504-507. [CrossRef] [PubMed]

42. Lutsey, P.L.; Parrinello, C.M.; Misialek, J.R.; Hoofnagle, A.N.; Henderson, C.M.; Laha, T.J.; Michos, E.D.; Eckfeldt, J.H.; Selvin, E. Short-term Variability of Vitamin D-Related Biomarkers. Clin. Chem. 2016, 62, 1647-1653. [CrossRef] [PubMed] 